Article

\title{
Spare Parts Cost Management for Long-Term Economic Sustainability: Using Fuzzy Activity Based LCC
}

\author{
Orlando Durán ${ }^{1, *}$, Paulo Sergio Afonso ${ }^{2}$ and Paulo Andrés Durán ${ }^{3}$ \\ 1 Escuela de Ingeniería Mecánica, Pontificia Universidad Católica de Valparaíso, 2430000 Valparaíso, Chile \\ 2 Departamento de Produção e Sistemas, Universidade do Minho, 4704-553 Braga, Portugal; \\ psafonso@dps.uminho.pt \\ 3 Area Mecánica, Universidad Tecnológica de Chile INACAP, 2430000 Valparaíso, Chile; \\ paulo.duran02@inacapmail.cl \\ * Correspondence: orlando.duran@pucv.cl
}

Received: 8 March 2019; Accepted: 19 March 2019; Published: 27 March 2019

\begin{abstract}
The concept of life cycle sustainability assessment provides an interdisciplinary space to discuss the main challenges in addressing sustainability from a long-term perspective. However, uncertainty related to cost parameters constitutes one of the main challenges in LCC. This uncertainty prevents managers from precisely anticipating the exact values of important variables. These variables include the costs of spare parts inventories, which in some cases can constitute high percentages of the total cost of a product or service. We propose an activity-based costing model that handles uncertainty using triangular numbers, along with a matrix representation, and Weibull functions to incorporate the projected equipment reliability into the model. A case study based on a spare parts distribution center, which serves the mining industry in Northern Chile, is presented. The results obtained are compared with a traditional costing method. The advantage of using the proposed approach over the traditional one is evident. Future research is directed towards the implementation of a larger number of inventory policies, along with experimentation with other types of fuzzy numbers.
\end{abstract}

Keywords: activity-based costing; spare parts; fuzzy; uncertainty; economic sustainability

\section{Introduction}

The concept of life cycle sustainability assessment [1] was created in order to provide an interdisciplinary space in which specialists, from different disciplinary fields, could discuss the main challenges in addressing sustainability with a life cycle perspective. Wood and Hertwich [2], discussed the role of Life Cycle Costs (LCC), assuming that sustainability is a concept defined at the macro organizational level, and economic sustainability is one of the key elements of such a level. Supply chain and logistics are important for such perspective [3,4], acting as an integrating factor in the overall business scenario. In this context, and according to Rezaee [3], there is the need for a pragmatic methodology to assess business sustainability.

According to [5], Total Costs of Ownership (TCO) and LCC are models that allow a more accurate and complete assessment of all costs that are related to investment decisions or purchasing activities. Furthermore, two highly-cited works [6,7] included reliability factors in an attempt to improve the accuracy of such models. One of the most important elements of such costs are operating and support costs, which are also usually the most difficult to predict [8]. Indeed, operating costs could even reach 10 times the purchase equipment cost [9]; therefore, they must be modelled properly, including the different non-reliability related costs. Garetti and Roda [10] proposed a framework that addresses the benefits of the total cost of ownership methodology in decision-making. In such a framework, 
based on TCO analysis, distinctions are made regarding the phase of an asset's life cycle. The main differences are related to the reliability behavior in the different phases of the life cycle. Besides, the authors suggested a Cost Breakdown Structure (CBS) to differentiate and deploy a series of costs categories. In such structure, the two main categories are CAPEX and OPEX. In terms of OPEX, the maintenance visible costs are highlighted, where the cost of spare parts plays an important role in the aforementioned CBS.

Several authors have developed studies that aim to quantify spare parts-related costs. For instance, Ref. [11] carried out a maintenance benchmarking study in a series of Chilean open pit copper mines; in such study, maintenance was found, on average, to be responsible for $44 \%$ of productions costs. The same authors reported that spares and repairable parts constitute, on average, one-third of the maintenance costs.

In other industries, the situation is not different. In the aviation sector, the maintenance costs constitute approximately $10 \%$ to $15 \%$ of the total operating costs of an aviation company. Flint [12] established that, at that time, the global inventory of spare parts in the aviation industry amounted to $\$ 45$ billion. However, when considering the inventory value invested per aircraft in operation, this decreased from about $\$ 3.75$ million per aircraft in 1995 to about $\$ 3.35$ million per aircraft in 2002 . In other words, it remains a significant figure. This is mainly due to growth in the global number of aircraft in recent years. Therefore, any effort to reduce this stock, without reducing customer service, will be well received by the aviation industry. Despite a lot of efforts being focused on reducing such stocks, the figures were estimated to be over US\$50 billion in 2002 [13].

In the wind energy industry, spare parts are essential, because stockouts may cause prolonged downtimes periods, mainly because of long lead times and, usually, inclement weather conditions present in the sites where those physical assets are installed. Hence, stock holding is necessary to achieve high service levels, seeking short machine downtime. This can result in increased spare parts' holding costs [14]. In Germany, the Wind Energy Institute estimated service and spare parts costs as $26 \%$ of the variable costs for German turbines operation and maintenance costs [15]. More recently, [16] indicated that the relative OPEX share of total levelized costs of energy may vary from $13 \%$ to $57 \%$ over the life-cycle of an offshore wind farm. This adds another important aspect to the analysis of operation and maintenance costs, i.e., its wide variation between different cases and situations.

Any industrial system, especially those that store high-value items in their depots, have the need to control inventory costs to be efficient, both logistically and from a management point of view [17]. Nevertheless, little attention has been paid to determine the costs related to inventory management [18]. Among the cost elements, maintenance costs are possibly the most prominent. This is basically due to the high level of capital invested in inventories, the increased warehouse rents and write-offs, high salaries of warehouse staff, and other "out-of-pocket costs". Determination of appropriate holding costs is vital to any logistics management system. This is because such costs are extensively considered in highly disseminated inventory management models, such as the EOQ, Joint Economic Lot Size Analysis, and recently developed models. Unfortunately, estimates of the percentage that corresponds to holding costs vary significantly from case to case. For instance, Lambert and Stock [19] suggested that holding costs range between $12 \%$ and $34 \%$ depending on the industry/field. Clendenen and Rinks [20] assume that $30 \%$ of the cost of the product corresponds to the holding costs. Therefore, such costs are very difficult to estimate accurately, and are often defined by managers using subjective rules depending on the industry [17].

The variability of one of the most important cost parameters may have a great impact if it is not considered in long-term analysis. As is known, little local (short term) variations (i.e., lack of accuracy) in a cost parameter can result in significant deviations in overall costs, when such effects are considered from a long-term perspective.

Moreover, since these processes involve long-term decision making, they often deal with high degrees of uncertainty. This uncertainty prevents managers from precisely anticipating the exact values of important variables, such as future discount rate, unitary costs values, and demand pattern $[20,21]$. 
Several authors suggest the use of simulation models; however, these models lose precision and validity when sufficient data is not available to define the appropriate and representative probability distributions [22,23]. An alternative is use of the so-called fuzzy reasoning [24,25]. Through this technique, the decision-making processes can be carried out using incomplete, subjective, and fuzzy information [26-28].

Uncertainty is classified as random and epistemic. While the second type of uncertainty is considered reducible, the first type is not. The most used approach to deal with inherent (aleatory) uncertainty is the Montecarlo simulations (MCS) [29]. Farr et al. [30] argued about the usefulness of simulation-based costing during initial phases of system design, because that is when budgets are set. However, these simulation experiments require substantial data to compound useful and representative probability distributions [31]. On the other hand, fuzzy mathematics has been used when the available data was limited. Comparing both techniques, the authors found that fuzzy mathematics is a more conservative approach for risk assessment than MCS [30]. In an attempt to improve the accuracy of the LCC models, the activity-based costing approach has been included into LCC models. Kayrbekova et al. [32] highlighted the advantages of including such a costing technique. Among the advantages associated with the $\mathrm{ABC}$ approach, we can highlight that it follows a process-oriented perspective. On the other hand, activity-based costing allocates overhead costs more accurately than conventional approaches. In addition, $\mathrm{ABC}$ will make it possible to simultaneously analyze several alternatives of equipment. To the best of our understanding, no work has been undertaken on activity-based LCC that handles uncertainty in spare parts management. If we consider together the lack of accuracy in the computation of costs and the uncertainty related to the behavior of cost parameters and cost drivers, the dispersion to be obtained in the long-term cost values can be devastating. Here, we identify a research gap, which is the absence of life-cycle costing models that incorporate spare parts management, taking into account the uncertainty associated with long-term economic analysis.

Thus, this paper proposes an activity-based life cycle costing (AB-LCC) model, which uses fuzzy mathematics to identify costs of spare parts management during the life cycle of a physical asset or system. The main objective of the model is to allow decision-makers to perform assessments and select the most appropriate inventory parameters for a given set of spare parts, anticipating budgets, and/or determining logistics parameters. This approach represents a useful method to model and operate in scenarios when only diffuse information is available to make long-term assessments. The main contribution of the proposed model is aimed at providing better information for economic sustainability projections.

This paper is organized as follows. Section 2 presents a brief description of activity-based costing, along with a matrix representation of such a technique. Section 3 describes the use of Weibull distribution as a basis to forecast the future needs of spare parts in a physical assets system. In Section 4, the model is described. A case study based on a spare parts depot located in northern Chile is presented in Section 5. The results of the applications are presented and discussed in Section 6. Finally, in the last section, some considerations and reflections are provided.

\section{Activity Based Costing (ABC)}

Costs are classified as direct and indirect. Such classification is made considering if a cost is easily allocated or not to cost objects. Traditionally, indirect costs are allocated to cost objects using cost drivers related to the volume of production, such as labor or the amount of raw material used. Nevertheless, when the production volume is used as a cost driver, some costs cannot be easily allocated to the costs object. The correct allocation of indirect costs is crucial because the proportion of such costs has dramatically increased over the last few years. By applying a correct cost allocation method, managers will have useful information to lead actions such as cost management and optimization.

Traditionally, logistics costs have been considered as indirect [33]. Therefore, such costs are generally allocated using one of the two following techniques: 
1. The allocation process is based on simple criteria of allocation.

2. They are attached to a pool of costs; therefore, they are considered as overhead costs.

When an indirect cost is improperly allocated, a particular cost object could get a larger proportion of the indirect costs [34]. Correspondingly, a smaller fraction of the indirect costs will be allocated to other(s) cost object(s). Such situation may lead to inequities, which can affect the correct decision-making process.

In the field of spare parts logistics, such an imbalance can affect the correct decisions about, for instance, the stock or no stock decisions, lot sizing definition, inventory policy implementation. In many cases, such a situation could affect the long-term profitability of the organization.

Regarding the uncertainty in cost assessments, the American Institute of Chemical Engineers (AIChE) proposed the following five costs categories:

- Direct (capital and other investment costs)

- Indirect (operating expenditures and maintenance costs)

- Contingencies (unexpected situations)

- Intangible (client retention, employee motivation and performance), and, costs to society (external costs).

Each category is more difficult to quantify than previous categories. It is noteworthy that the higher the level of the cost category, the higher the uncertainty to quantify it.

One of the most accepted methods of tackling the difficulty of correctly allocating indirect costs is Activity Based Costing ( $A B C)$. The $A B C$ technique is based on a series of process maps. These maps are divided into a series of activities. An activity is defined by what an organization does, the time it spends on it, and what results from its execution. More specifically, the ABC model allocates resources' costs to a series of activities that are carried out to produce/handle cost objects, in this case, spare parts. In a second phase, the activity costs are allocated to cost objects.

Using the correct cost drivers for each activity, it is possible to precisely calculate the amount of resources that each cost object consumes.

Afonso and Paisana [35] proposed a matrix-based ABC algorithm. In this algorithm, data related to resources, activities, cost objects and drivers are expressed using vectors and matrices. Such algorithm comprises of two allocation phases. The first one consists of the computation of activity costs multiplying resource-activity matrix, $r_{i j}$, which represents the percentage of the resource-driver $j$ which is used by activity $i$, by a vector, $r_{j}$, that represents the total expenditure on the resource $j$ expended during a given period. The aforementioned multiplication generates the activities matrix $\left(a_{i}\right)$. In such a matrix, each term represents the cost allocated to each activity $i$. That operation is represented by Equation (1):

$$
a_{i}=\sum_{j=1}^{n} r_{i j} * r_{j}
$$

The second phase, which is aimed at obtaining the cost object matrix $\left(p_{k}\right)$, consists of the multiplication of the activity-product matrix $\left(a_{k i}\right)$ by the activity costs vector $\left(a_{i}\right)$. Note that each element of the activity-product matrix $\left(a_{k i}\right)$ represents the percentage of each activity related to each cost object $k$. That is, this percentage is obtained by the quotient of the quantity of the activity-driver $i$, related to the cost object $k\left(a_{k i}\right)$ and the total quantity of the activity-driver $i\left(a_{i}\right)$. Therefore, the costs allocated to each cost object are obtained through Equation (2):

$$
p_{k}=\sum_{i=1}^{m} a_{k i} * a_{i}
$$

Therefore, the cost-object matrix can be computed as shown by Equation (3):

$$
\left[a_{k i}\right] *\left[r_{i j}\right] *\left[r_{j}\right]=\left[p_{k}\right]
$$


In order to overcome the uncertainty related to the costing procedure, a fuzzy extension of the $A B C$ is proposed. In the next chapter, we will describe the proposed fuzzy $A B C$ model. In addition, an application case of the model applied to a spare parts warehouse will be presented.

\section{Weibull-Based Reliability Equations}

The Weibull statistical distribution is one of the most used functions to represent the behavior of reliability throughout the life of a physical asset. The reliability of a component can be represented by Equation (4) [36]:

$$
R(t)=e^{-\left(\frac{t-t_{0}}{\eta}\right)^{\beta}}
$$

where $\beta$ is the shape parameter and characterizes the failure pattern. The higher the value of $\beta$, the greater the failure probability in a given period of time. The time $t_{0}$ corresponds to the location parameter and provides an estimation of the earliest time at which a failure may be observed. Also, it can represent the beginning of the deterioration process of the equipment. Finally, $\eta$ is the scale parameter and represents the characteristic life of the equipment. This parameter corresponds to the time in which $63.2 \%$ of the failures are expected to occur. Therefore, having the Weibull parameters, it is possible to estimate the failure rate for a given component in time $t(\lambda(t))$. Equation (5) shows the relationship between $\beta, \eta$ and $\lambda$ :

$$
\lambda(t)=\frac{\beta}{\eta}\left(\frac{t}{\eta}\right)^{\beta-1}
$$

One of the most traditional ways to represent the phases of the life cycle of a physical asset over time is the bathtub curve (Figure 1). This curve shows the behavior of failure rate over time. The bathtub curve consists of three phases-the infant mortality period, where the failure rate $(\lambda)$ decreases over time; the useful life, where $\lambda$ remains constant; and the end-of-life phase, also called the wear out phase. In such a phase, $\lambda$ begins to increase in time to the point where it is decided to discard the equipment or decommission the installation.

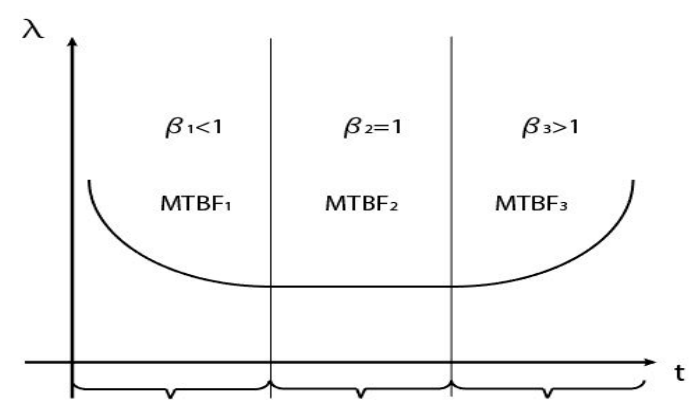

Figure 1. Bathtub curve of a physical asset.

As already mentioned, these different phases of the life cycle have different characteristics in terms of reliability and failure rate. Table 1 summarizes these characteristics.

Table 1. Behavior of the Weibull parameters according to the stage of the life cycle.

\begin{tabular}{cl}
\hline Value & Characteristic \\
\hline$\beta<1$ & $\lambda$ decreases with age, without reaching zero. \\
$\beta=1$ & $\lambda$ remains constant, with random occurrences. \\
$1<\beta$ & $\lambda$ increases with age on an ongoing basis. \\
\hline
\end{tabular}

As expected, when the aforementioned Weibull parameters of a component change over the life cycle, the failure rate is affected. If we consider that each failure constitutes the need for component substitution, any change in failure rate will influence the demand pattern of spare parts at the depot 
level. Therefore, future spare parts' demand at the warehouse could be modelled using this distribution. As commented above, $(\lambda(t))$, can be estimated using Equation (5). Basically, the Weibull-based model allows the estimation of the failure rates and corresponding spare parts' demand.

\section{Proposed Model}

In methodological terms, what is proposed here is a generic logistics process for spare parts management, modeled using the activity-based approach. A series of resources, with their respective costs, are considered for the execution of such logistics activities. Relevant cost drivers are selected for each activity and for each resource group. To include uncertainty handling into the model, the main variables of the model are represented as triangular numbers. These values are processed in combination with crisp values because of their deterministic character. To estimate the future demand of the spare parts, a model based on the two-parameter Weibull distribution is applied. Through this model, it is possible to measure the effect on life cycle costs caused by the variation of different inventory policies or parameters in a long-term perspective considering uncertainties.

In general terms, the present value of the global costs of management critical non-repairable spare parts inventories along the entire life cycle can be modelled as follows:

$$
G C i=D C i+H C i+L C_{i}
$$

where

$D C_{i}=$ Present value of the direct costs of item $i$

$H C_{i}=$ Present value of the capital costs of item $i$

$L C_{i}=$ Present value of the logistics costs of item $i$

Rewriting the first two elements of the equation, Equation (6) can be expressed as:

$$
G C_{i}=c_{i} \cdot \lambda_{i}+\frac{h_{i} \cdot Q_{i}}{2}+L C_{i}
$$

where:

$c_{i}=$ unitary cost of item $i$

$\lambda_{i}=$ demand on item $i$

$Q_{i}=$ replenishment lot size of item $i$

$h_{i}=$ capital cos ts of item $i$

An $\mathrm{ABC}$ methodology is proposed to compute $L C_{i}$ costs. The implementation of the logistics costs assessment under uncertainty is explained in the next paragraphs. For such an objective, we propose to include triangular numbers within the costing procedure.

A fuzzy number denotes the meaning of statements such as 'around $x^{\prime}$. Such a meaning is represented by a membership function [37]. A membership function $\mu(x)$ can be defined as a triplet $\left(a_{1}\right.$, $\left.a_{2}, a_{3}\right)$. Therefore, the triangular numbers represent the result of the membership function as shown in Equation (8) and illustrated in Figure 2.

$$
\mu(\mathrm{x})= \begin{cases}1 & x=a_{2} \\ \frac{x-a_{1}}{a_{2}-a_{1}} & a_{1} \leq x<a_{2} \\ \frac{a_{3}-x}{a_{3}-a_{2}} & a_{2}<x \leq a_{3} \\ 0 & \text { otherwise }\end{cases}
$$




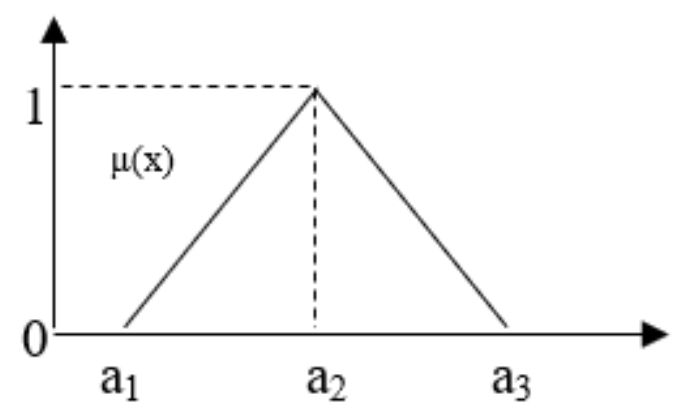

Figure 2. Membership function of a triangular number.

To operate with triangular numbers, a set of mathematical operations is needed. Such mathematical operations over triangular fuzzy numbers were defined by [38] and are briefly explained in the following:

Let $\widetilde{A}$ and $\widetilde{B}$ be two triplets; the parameters of these triplets are defined as follows:

$$
\widetilde{A}=\left(a_{1}, a_{2}, a_{3}\right) \widetilde{B}=\left(b_{1}, b_{2}, b_{3}\right)
$$

Table 2 shows the main operations used by fuzzy mathematics.

Table 2. Main operations used by fuzzy mathematics.

Product of a pair of fuzzy numbers

Fuzzy numbers division

The reciprocal of a triangular number $\left(a_{1}, a_{2}, a_{3}\right)$

Conversion the triangular number into a crisp one

(defuzzification),

$$
\begin{gathered}
\widetilde{A} \widetilde{B}=\left(a_{1} b_{1}, a_{2} b_{2}, a_{3} b_{3}\right) \\
\widetilde{\widetilde{A}}=\left(a_{1} / b_{1}, a_{2} / b_{2}, a_{3} / b_{3}\right) \\
\widetilde{A^{n}}=\left(a_{1}, a_{2}, a_{3}\right)^{n}=\left(a_{1}^{n}, a_{2}^{n}, a_{3}^{n}\right) \\
A=\frac{a_{1}+2 \cdot a_{2}+a_{3}}{4}
\end{gathered}
$$

Returning to the proposed model, we adapted the model created by [35] to accept three new assumptions:

- The life cycle concept (multiperiod)

- The fuzziness of variables (triangular numbers)

- The Weibull-based reliability of the components (reliability model)

First of all, we propose a fuzzy-based model that uses the matrix representation of the ABC approach. In such representation, each element of the matrix used in the ABC matrix-based model is represented by triplets. Accordingly, we have rewritten Equation (3) to represent its elements as fuzzy ones:

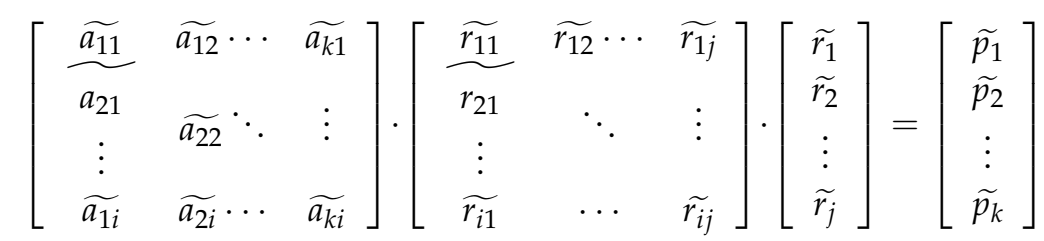

Therefore, the life cycle costs of spare parts management for a period of $c v$ years, $T$ types of spare parts, $M$ categories of resources and $N$ activities will be given by the present value of the sum of the global cost of the $c v$ periods of the life cycle:

$$
G C=\sum_{y=1}^{c v} \frac{1}{\left(1+\widetilde{t d}_{y}\right)^{y}}\left[\sum_{k=1}^{T} \widetilde{C}_{k y} \cdot \lambda_{k y}+\frac{\left(\widetilde{H}_{k y} \cdot Q_{k y}\right)}{2}+\sum_{k=1}^{T} \sum_{i=1}^{N} \sum_{j=1}^{M} \widetilde{a}_{k i y} \cdot \widetilde{r}_{i j y} \cdot \widetilde{r}_{j y}\right]
$$

It is worth noting that we have incorporated two variables oriented to the evaluation of costs under the life cycle approach. We refer to the capitalization factor, $\left(1+t d_{y}\right)^{y}$, which is affected by the 
expected discount rate for the period $t d_{y}$. Secondly, variable $y$ is considered to represent each one of the periods of the life cycle. The parameters using the symbol correspond to a triangular number. Last, but not least, and how it was aforementioned, the demand is modelled using the Weibull distribution.

To illustrate the application and to validate the proposed model, a case study is presented and discussed. In such a study, it is possible to compute the present value of the logistics costs of the spare parts management considering uncertainty. Furthermore, it was possible to assess the impact of the variation of some of the variables of the model, such as lot sizes and uncertainty levels. The results of that study are shown and discussed in the next section.

\section{Case Study}

The following is an example of application to demonstrate the usefulness and feasibility of the proposed model. The differences between conventional LCC and Fuzzy-AB-LCC are analyzed and discussed. For simplicity, this case study considers three activities carried out in a logistics and distribution center that stores a certain number of spare parts and serves a group of mining operations located in northern Chile. These spare parts are intended for large loading and hauling equipment. At the present moment, this unit stores approximately 8100 different items, which represents an investment of around 4.1 million euros. Qualitative interview data were combined with quantitative analysis of data from ERP databases. This improved the reliability of the information collected.

As aforementioned, this center provides a full logistics service for a series of operational units (mining pits), including receiving spare parts from OEMs major units, put-away and storage items, inventory management and care activities, picking and preparation of orders, and shipping.

First, the resources and their related amounts were extracted using the ERP system. Table 3 shows the list and values of the main resources consumed by the warehouse operation on an annual basis.

Table 3. Resources consumed by the warehouse (€/year).

\begin{tabular}{ccc}
\hline No. & Resources & Values $(€)$ \\
\hline 1 & Warehouse staff salaries & $€ 171,428.57$ \\
2 & Rent and insurances & $€ 171,771.43$ \\
3 & Handling equipment (little) & $€ 29,142.86$ \\
4 & Handling equipment (big) & $€ 34,285.71$ \\
5 & Services and utilities & $€ 685.71$ \\
6 & IT \& communications & $€ 857.14$ \\
7 & Materials & $€ 1714.29$ \\
\hline & Total & $€ 409,885.71$ \\
\hline
\end{tabular}

Second, we mapped the main activities developed in the spare parts warehouse. For simplicity, we aggregated the activities into three main classes. These activities, with their respective drivers, are presented in Table 4 .

Table 4. Activities executed by the warehouse.

\begin{tabular}{ccc}
\hline No. & Activities & Driver \\
\hline 1 & Ordering and receiving & Lots received \\
2 & Put away, storage and caring & Complexity index \\
3 & Picking, sorting and shipping & Lots delivered \\
\hline
\end{tabular}

For the same reason, we grouped the existent spare parts into three main categories. Each one of those categories have important differences in general characteristics, such as weight, fragility, care and attention needs, and quantities.

Finally, we assumed a life cycle of nine periods (years). Besides, the life cycle was divided into three phases: Beginning of life (BOL), middle of life (MOL) and end of life (EOL), with a three-year 
extension each. To model future demands of the spare parts, we assumed that the Weibull distribution was representative. In order to demonstrate the feasibility and utility of the model, three different demand patterns were considered, one for each spare part category. Therefore, the Weibull's parameters were defined separately for each life cycle phase, providing a more realistic representation of the demand patterns in each category. Table 5 summarizes those parameters for each phase and for each spare part class.

Table 5. Weibull parameters.

\begin{tabular}{ccccccc}
\hline \multirow{2}{*}{ Spare Parts Type } & \multicolumn{2}{c}{ Phase 1 (BOL) } & \multicolumn{2}{c}{ Phase 2 (MOL) } & \multicolumn{2}{c}{ Phase 3 (EOL) } \\
\cline { 2 - 7 } & $\boldsymbol{\beta}$ & $\boldsymbol{\eta}$ & $\boldsymbol{\beta}$ & $\boldsymbol{\eta}$ & $\boldsymbol{\beta}$ & $\boldsymbol{\eta}$ \\
\hline 1 & 1 & 860 & 1 & 860 & 1 & 860 \\
2 & 1.5 & 124 & 1.5 & 124 & 1.5 & 124 \\
3 & 0.8 & 3500 & 1 & 1200 & 1.35 & 250 \\
\hline
\end{tabular}

Figure 3 schematically shows the three-demand pattern, accordingly to Weibull's parameters defined for each spare part class.

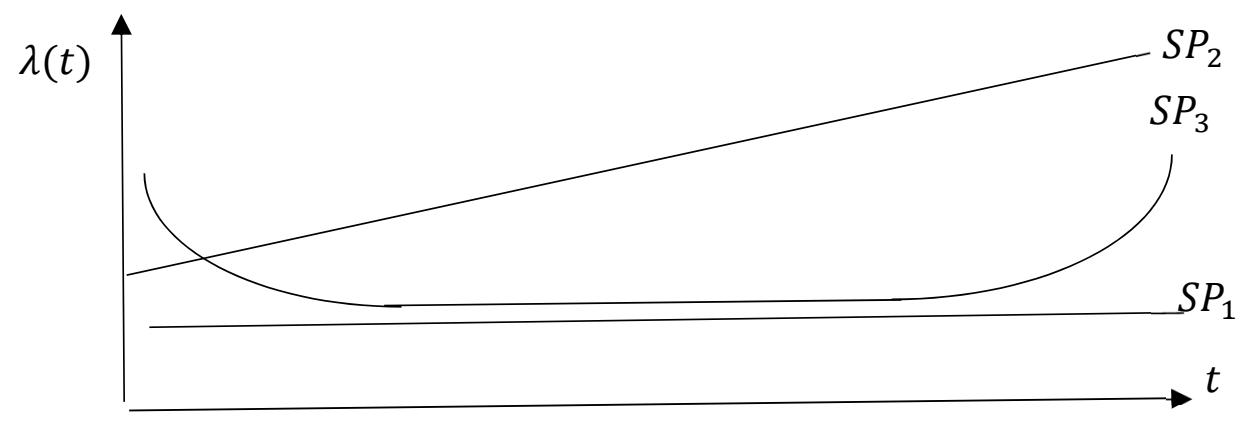

Figure 3. The three-demand pattern.

To include future uncertainty, the cash-flow associated with the resources' costs were treated as triangular numbers. For that, the initial values of those costs were transformed into triplets, according to the process explained in Section 3. Besides, an inflation rate was applied to define the future values of those costs, set at $4 \%$ per year. The discount rate assumed in this example was $30 \%$ per year. Table 6 shows the main characteristics of each one of the spare part categories, which generated measurable effects into costing process results and allowed us to define the activities' consumption percentages.

Table 6. Activities executed by the warehouse.

\begin{tabular}{cccccc}
\hline Spare Class & Weight & Size & Demand/Rotation & Care Needs & Criticality \\
\hline 1 & High & Big & Low & High & High \\
2 & Low & Small & High & Low & Low \\
3 & High & Large & Medium & Very High & High \\
\hline
\end{tabular}

The combination of demand levels, together with the activity drivers over the periods, generated different activity consumption ratios, which affect the costs allocated to each category of spare parts. Table 7 shows the operating parameters considered for each spare part class. Note that the consumption volumes correspond to the values of the first period, and that they vary in each period, according to the respective Weibull function parameters. 
Table 7. Spare parts (initial) parameters.

\begin{tabular}{cccc}
\hline Spare Part Class & $\begin{array}{c}\text { Demand } \\
\text { (unit/period) }\end{array}$ & $\begin{array}{c}\text { Purchasing Lot Size } \\
\text { (unit/lot) }\end{array}$ & $\begin{array}{c}\text { Internal Lot Size } \\
\text { (unit/lot) }\end{array}$ \\
\hline 1 & 10 & 1 & 1 \\
2 & 1000 & 100 & 10 \\
3 & 100 & 10 & 5 \\
\hline
\end{tabular}

The following section shows the results obtained. In addition, several situations were analyzed to evaluate the usefulness of the proposed model, as well as to compare it with the use of traditional allocation methods.

\section{Results and Discussion}

Table 8 shows the triangular numbers that represent the present values of the total costs for each spare part category. The correspondent crisp number is also included in the same table.

Table 8. Present values of total costs for each spare part category (triangular and crisp representation).

\begin{tabular}{ccccc}
\hline Spare Part Class & $\boldsymbol{a}_{\mathbf{1}}$ & $\boldsymbol{a}_{\mathbf{2}}$ & $\boldsymbol{a}_{\mathbf{3}}$ & Crisp \\
\hline 1 & $€ 226,691.40$ & $€ 283,364.25$ & $€ 349,898.00$ & $€ 285,829.48$ \\
2 & $€ 541,040.58$ & $€ 676,300.73$ & $€ 834,188.47$ & $€ 681,957.63$ \\
3 & $€ 324,181.20$ & $€ 405,226.50$ & $€ 501,077.81$ & $€ 408,928.00$ \\
\hline
\end{tabular}

Table 9 shows the comparison of the activity-based system with a traditional costing system, based on the volume of parts handled in the warehouse. Consider that, for this purpose, unit costs were calculated considering the volumes handled in each period.

Table 9. Present values of unitary costs for each spare part category (traditional costing and ABC).

\begin{tabular}{ccc}
\hline Spare Part Class & ABC & Traditional Costing \\
\hline 1 & $€ 28,582.95$ & $€ 1008.22$ \\
2 & $€ 681.96$ & $€ 1267.38$ \\
3 & $€ 4089.28$ & $€ 874.33$ \\
\hline
\end{tabular}

Figure 4 and Table 9 show the behavior of the unit costs obtained by using both costing systems. Note how the traditional costing system does not reflect significant difference between the different parts' categories.

Such differences between the two systems can lead to wrong decisions. For example:

1. Deciding on the types of parts to keep in the warehouse. Usually, managers take this decision by considering the unit costs obtained by traditional systems. The model proposed here allows to take into account reliability parameters and the "efforts" (i.e., resources consumption) that must be made in the warehouse to define whether or not it is possible to maintain a certain type of spare part in the warehouse. Observe how the traditional costing system does not distinguish between the three categories of spare parts. Using the ABC, the fact that SP1 parts are heavier, voluminous, and need relatively important care in the warehouse is reflected in their unit costs.

2. The information in Table 9 can be useful to develop life cycle budgets or to plan future cash flows. Note that under the traditional system, the total costs related to SP1 are virtually insignificant, which could lead to unbalanced decisions (such as allocating fewer resources to SP1, ignoring that this category needs more care than SP2), for which are allocated the highest level of resources.

3. Figure 5 shows the triangular values $\left(a_{1}, a_{2}, a_{3}\right)$ of total costs related to each category of spare parts. If a pair of values overlap, the relationships "greater than" or "less than" can be maintained with a 
lesser degree of certainty. On the other hand, when two triangular values do not overlap (Figure 6), the degree of confidence in comparing them will be greater. This will have repercussions on the decision-making process.

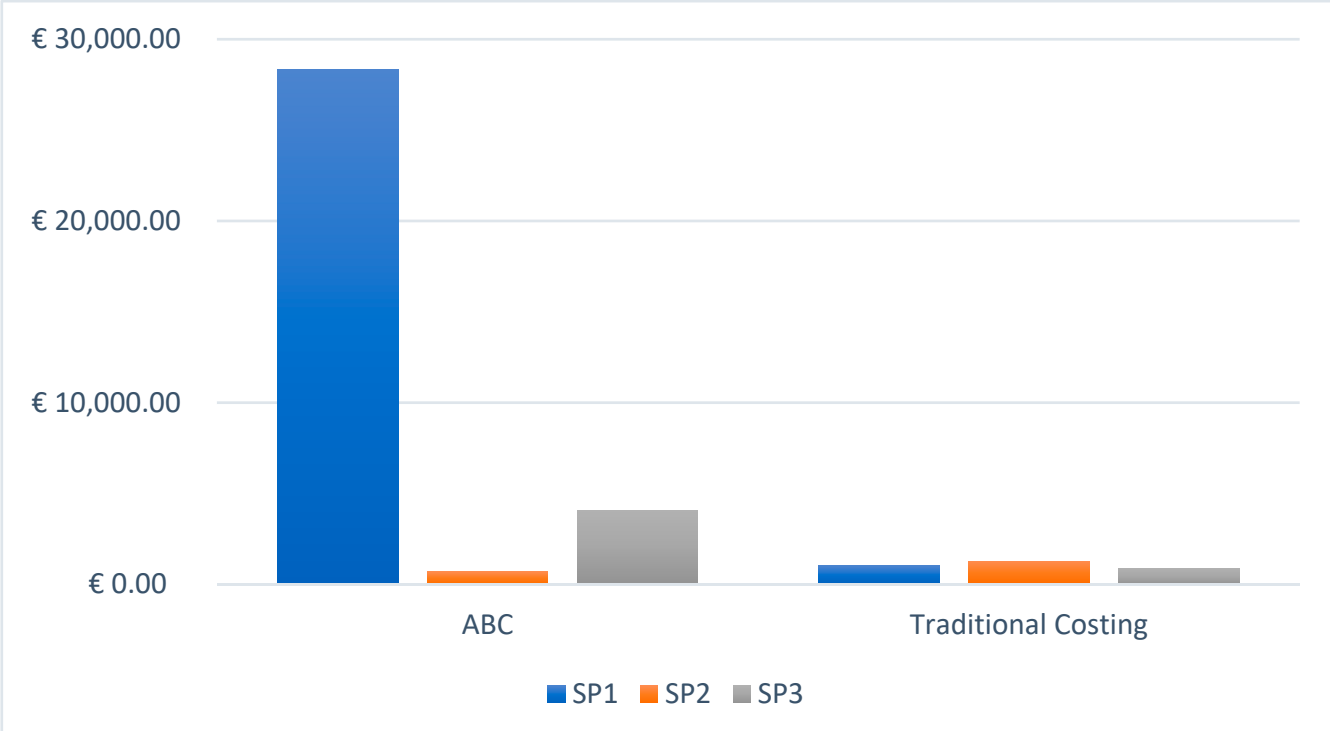

Figure 4. Unit costs computed using the proposed model and the traditional costing system.

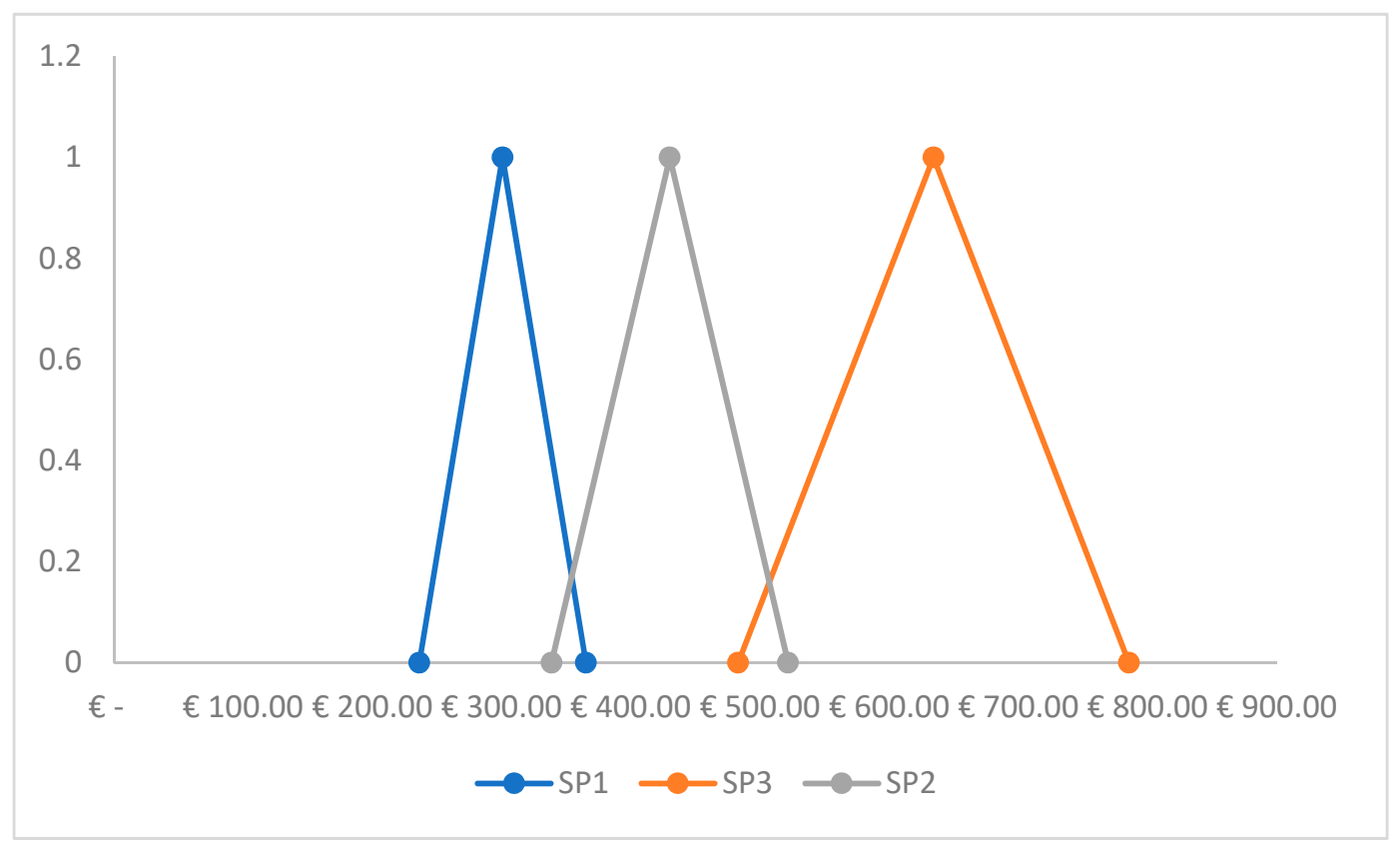

Figure 5. Triangular values of total costs for each type of spare part. 


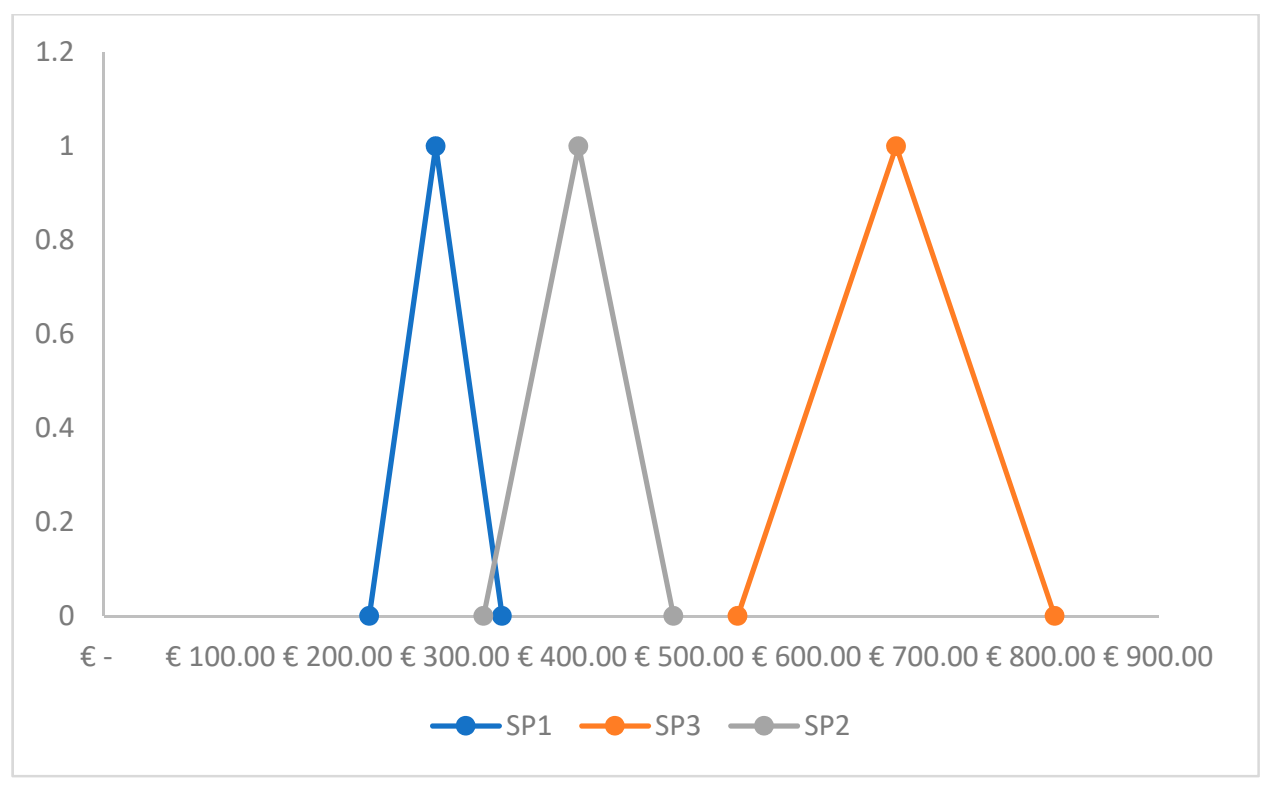

Figure 6. Present triangular values of spare part categories' total costs.

The impact of higher levels of uncertainty related to resource 4 was also analyzed. Along with this, the reformulation of the use of resource 3 was considered, assigning it exclusively to activity 2 . The behavior of the present value considering this situation is shown in Figure 6.

On comparing Figures 5 and 6, an increase in the present value of the total costs associated with SP1 and SP3, together with a reduction in the costs of SP2, can be observed. This indicate that this reduction seems more appropriate, since SP1 and SP3 correspond to the heaviest and most voluminous categories. This should be reflected in the amount of resources consumed by these types of spare parts, in comparison with lighter spare parts that require less care, thus lower levels of resource consumption. This change should be supported by changes in operations that were not considered here. Nevertheless, the proposed model offers relevant information for the implementation of such changes at both operational and strategic levels.

\section{Final Considerations}

The assessment of economic sustainability in capital-intensive organizations should incorporate adequate means of decision-making to manage such assets, ensuring the highest levels of reliability and maintainability. In these organizations, the availability of high assets depends to a large extent on having an adequate level of spare parts in the warehouses. The correct long-term definition of warehouse stock levels can greatly benefit the economic sustainability of the organization. However, those levels are limited by constrained budgets.

This paper proposes a life cycle costing model for spare parts management to support the sustainability assessment of capital-intensive organizations. The proposed model is based on the application of activity-based costing and the $\mathrm{ABC}$ matrix algorithm. Along with this, and as a means of incorporating uncertainty into the cost analysis, triangular or fuzzy numbers were used to model the behavior of costs and resource consumption in the future.

The use of triangular numbers provides additional information regarding the best and worst scenarios for life cycle costing. Because of its long-term perspective and strategic nature, this approach provides more useful information for decision-makers. Besides, as an attempt to attain a more realistic representation of the behavior of the future demand for spare parts, the model incorporates the Weibull function as a reliability and failure representation. In addition, the model accepts any number of activities, spare parts, and resources. It is also possible to modify the number of periods considered and the demand patterns (failures) of each class of component, which offer the model great flexibility. 
An applied case study based on a spare parts distribution center for the mining industry in Northern Chile was presented. This case study revealed some findings, which reveal the utility of using the fuzzy-ABC based approach to quantify spare parts management costs in the long term. It was also observed that, in spite of using a reduced number of activities to map logistic processes, the representativeness of the results obtained exceeds those obtained by traditional costing methods.

Future developments point to the application of other inventory policies, experimentation with other types of fuzzy numbers, and application of the proposed model with a larger number of variables represented as triangular numbers. Also, it seems possible to easily transform the proposed model into an optimization model, incorporating restrictions such as a given budget, capacities, specific lot sizes and replenishments frequencies.

Author Contributions: O.D. designed the research, P.S.A. contributed to the development of the model, and result analysis and P.A.D. contributed to the writing and editing of the manuscript.

Funding: This research was funded by Fondecyt Regular n 1170915, Conicyt, Chile.

Acknowledgments: The first author would like to acknowledge the funding of Fondecyt Regular $\mathrm{n}^{\circ} 1170915$ : "Design and optimization of a life cycle based critical spare parts management system".

Conflicts of Interest: The authors declare no conflict of interest.

\section{References}

1. Zamagni, A. Life cycle sustainability assessment. Int. J. Life Cycle Assess. 2012, 17, 373. [CrossRef]

2. Wood, R.; Hertwich, E.G. Economic modelling and indicators in life cycle sustainability assessment. Int. J. Life Cycle Assess. 2012, 18, 1710-1721. [CrossRef]

3. Rezaee, Z. Supply chain management and business sustainability synergy. Sustainability 2018, 10, 275. [CrossRef]

4. Jin, S.H.; Jeong, S.J.; Kim, K.S. A Linkage Model of Supply Chain Operation and Financial Performance for Economic Sustainability of Firm. Sustainability 2017, 9, 139. [CrossRef]

5. Maisenbacher, S.; Klöppel, M.; Laubmann, J.; Behncke, F.; Mörtl, M. Integrated value engineering: Consideration of total cost of ownership for better concept decision. Target 2016, 1, C3.

6. Woodward, D.G. Life cycle costing-Theory, information acquisition and application. Int. J. Proj. Manag. 1997, 15, 335-344. [CrossRef]

7. Woodhouse, J. Managing Industrial Risk: Getting Value for Money in Your Business; Chapman \& Hall: London, UK, 1993.

8. Wilson, R.L. Operations and support cost model for new product concept development. Comput. Ind. Eng. 1986, 11, 128-131. [CrossRef]

9. Polo, F.A.O.; Bermejo, J.F; Fernández, J.F.G.; Márquez, A.C. Failure mode prediction and energy forecasting of PV plants to assist dynamic maintenance tasks by ANN based models. Renew. Energy 2015, 81, 227-238. [CrossRef]

10. Roda, I.; Garetti, M. Application of a performance-driven Total Cost of Ownership (TCO) evaluation model for physical asset management. In 9th WCEAM Research Papers; Springer: Cham, Switzerland, 2015; pp. 11-23.

11. Knights, P.F;; Oyanader, P. Best-in-class maintenance benchmarks in Chilean open pit mines. CIM Bull. 2005, $98,93$.

12. Flint, P. Too much of a good thing. Better management of inventory could save the industry millions. Air Transp. World 1995, 32, 103-108.

13. McDonald, M. Custom Tuning: The many variables affecting the maintenance supply chain make the coveted savings elusive. ATW Air Transp. World 2002, 39, 48-50.

14. Schuh, P.; Schneider, D.; Funke, L.; Tracht, K. Cost-optimal spare parts inventory planning for wind energy systems. Log. Res. 2015, 8, 4. [CrossRef]

15. Blanco, M.I. The economics of wind energy. Renew. Sustain. Energy Rev. 2009, 13, 1372-1382. [CrossRef]

16. Poulsen, T.; Hasager, C.B.; Jensen, C.M. The Role of Logistics in Practical Levelized Cost of Energy Reduction Implementation and Government Sponsored Cost Reduction Studies: Day and Night in Offshore Wind Operations and Maintenance Logistics. Energies 2017, 10, 464. [CrossRef] 
17. Azzi, A.; Battini, D.; Faccio, M.; Persona, A.; Sgarbossa, F. Inventory holding costs measurement: A multi-case study. Int. J. Log. Manag. 2014, 25, 109-132. [CrossRef]

18. Berling, P. Holding cost determination: An activity-based cost approach. Int. J. Prod. Econ. 2008, 112, 829-840. [CrossRef]

19. Lambert, D.M.; Stock, J.R. Strategic Logistics Management; Irwin: Homewood, IL, USA, 1993; Volume 69.

20. Clendenen, G.W.; Rinks, D. The effect of labour costs, holding costs, and uncertainty in demand on pull inventory control policies. Int. J. Prod. Res. 1996, 34, 1725-1738. [CrossRef]

21. Sun, Y.; Carmichael, D.G. Uncertainties related to financial variables within infrastructure life cycle costing: A literature review. Struct. Infrastruct. Eng. 2017. [CrossRef]

22. Nachtmann, H.; Needy, K.L. Methods for handling uncertainty in activity-based costing systems. Eng. Econ. 2003, 48, 259-282. [CrossRef]

23. Goh, Y.M.; Newnes, L.B.; Mileham, A.R.; McMahon, C.A.; Saravi, M.E. Uncertainty in Through-Life Costing-Review and Perspectives. IEEE Trans. Eng. Manag. 2010, 57, 689-701. [CrossRef]

24. Byrne, P. Fuzzy DCF: A contradiction in terms, or a way to better investment appraisal. In Proceedings of the Cutting Edge '97 Conference, RICS, Dublin, Ireland, 5-6 September 1997.

25. Chiu, C.Y.; Park, C.S. Fuzzy cash flow analysis using present worth criterion. Eng. Econ. 1994, 39, $113-138$. [CrossRef]

26. Gregory, J.R.; Montalbo, T.M.; Kirchain, R.E. Analyzing uncertainty in a comparative life cycle assessment of hand drying systems. Int. J. Life Cycle Assess. 2013, 18, 1605-1617. [CrossRef]

27. Kishk, M. Combining various facets of uncertainty in whole-life cost modelling. Constr. Manag. Econ. 2004, 22, 429-435. [CrossRef]

28. Kishk, M.; Al-Hajj, A. A fuzzy model and algorithm to handle subjectivity in life-cycle costing-based decision-making. J. Financ. Manag. Prop. Constr. 2002, 5, 93-104.

29. Rodríguez Rivero, E.J.; Emblemsvåg, J. Activity-based life-cycle costing in long-range planning. Rev. Acc. Financ. 2007, 6, 370-390. [CrossRef]

30. Farr, J.V.; Faber, I.J.; Ganguly, A.; Martin, W.A.; Larson, S.L. Simulation-based costing for early phase life cycle cost analysis: Example application to an environmental remediation project. Eng. Econ. 2016, 61, 207-222. [CrossRef]

31. Davidson, V.J.; Ryks, J. Comparison of Monte Carlo and fuzzy math simulation methods for quantitative microbial risk assessment. J. Food Protect. 2003, 66, 1900-1910. [CrossRef]

32. Kayrbekova, D.; Markeset, T.; Ghodrati, B. Activity-based life cycle cost analysis as an alternative to conventional LCC in engineering design. Int. J. Syst. Assur. Eng. Manag. 2011, 2, 218-225. [CrossRef]

33. Burritt, R.; Schaltegger, S. Accounting towards sustainability in production and supply chains. Br. Acc. Rev. 2014, 46, 327-343. [CrossRef]

34. Kaplan, R.S. Cost E Effect: Using Integrated Cost Systems to Drive Profitability and Performance; Harvard Business Press: Boston, MA, USA, 1998.

35. Afonso, P.S.; Paisana, A.M. An algorithm for activity-based costing based on matrix multiplication. In Proceedings of the IEEE International Conference on Industrial Engineering and Engineering Management, Hong Kong, China, 8-11 December 2009; pp. 920-924.

36. Murthy, D.N.P.; Xie, M.; Jiang, R. Weibull Models; Wiley: Hoboken, NJ, USA, 2004.

37. Zadeh, L.A. Information and control. Fuzzy Sets 1965, 8, 338-353.

38. Chang, D.Y. Applications of the extent analysis method on fuzzy AHP. Eur. J. Oper. Res. 1996, 95, 649-655. [CrossRef]

(C) 2019 by the authors. Licensee MDPI, Basel, Switzerland. This article is an open access article distributed under the terms and conditions of the Creative Commons Attribution (CC BY) license (http:/ / creativecommons.org/licenses/by/4.0/). 